\title{
Profesi Host yang Tercermin dalam Manga Hosutan e Youkoso Karya Makoto Tateno
}

\author{
Ni Putu Rica Garwita Juniari ${ }^{{ }^{*}}$, Ni Luh Putu Ari Sulatri ${ }^{2}$ \\ Program Studi Sastra Jepang Fakultas Ilmu Budaya, Universitas Udayana \\ ${ }^{1}$ [email: rgarwita@gmail.com], ${ }^{2}$ [email: ari_sulatri@unud.ac.id] \\ *Corresponding Author
}

\begin{abstract}
Abstrak
Penelitian ini berjudul "Profesi Host yang Tercermin dalam Manga Hosutan e Youkoso karya Makoto Tateno". Penelitian ini bertujuan untuk mengetahui kriteria untuk menjadi host serta profesi host yang tercermin dalam manga Hosutan e Yokoso karya Makoto Tateno. Penelitian ini menggunakan teori sosiologi sastra dari Ratna (2009), teori trilogi sastra dari Wellek dan Warren (1993), dan teori semiotika dari Danesi (2012). Metode yang digunakan untuk menganalisis data adalah metode kualitatif dan teknik deskriptif analisis. Hasil analisis menunjukkan bahwa kriteria untuk menjadi host terbagi menjadi dua kriteria yaitu, kriteria fisik dan kriteria non fisik. Kriteria fisik untuk menjadi host terbagi menjadi dua bagian yaitu, 1) memiliki wajah yang menarik; serta 2) berpenampilan yang baik. Kriteria non fisik untuk menjadi host terbagi menjadi lima bagian yaitu, 1) memiliki toleransi tinggi terhadap minuman beralkohol; 2) memiliki keterampilan dalam berkomunikasi terutama dengan pelanggan; 3) memiliki wawasan yang luas; 4) mampu menyesuaikan diri dengan kebutuhan pelanggan; serta 5) berusia 20 tahun hingga 30 tahunan. Profesi host yang tercermin dalam manga Hosutan e Youkoso terbagi atas 1) tugas host; 2) level host; 3) jam kerja host; 4) penghasilan host; 5) identitas host; serta 6) host club. Tugas host terdiri dari tiga yaitu, 1) menyambut pelanggan; 2) menemani pelanggan; serta 3) memberikan perhatian kepada pelanggan. Level host dibagi menjadi dua yaitu, 1) host nomor satu; serta 2) host sebagai herupu 'host junior yang membantu host nomor satu di host club'.
\end{abstract}

Kata kunci: mizu shoubai, host club, host

\begin{abstract}
This research's title is "Host Profession which had Reflected in Manga Hosutan e Youkoso by Makoto Tateno". This research aimed to know the criteria to be a host in a host club in Japan. This research used the sociology of literature theory by Ratna (2009), literary trilogy theory by Wellek and Warren (1993), and semiotics theory by Danesi (2012). The results of this research showed that there are two criteria to be a host, i.e. physical criteria and non-physical criteria. In detailed, has an attractive face and has a good looking respectively. On the other hand, there are five parts of non-physical criteria to be a host, which have tolerance to alcoholic beverages, have skills to communicate with costumers, have a broad insight, adjusted well with costumer needs, and should be between 20 years to 30 years. Host profession which had reflected in manga Hosutan e Youkoso are host assignment, host level, working hours of host, host earnings, host identity, and host club. There are three parts of host assignment, i.e. welcoming costumers, assisting the costumers, and giving attention to costumers. Moreover, there are two parts of host level, that are number one host and host as herupu 'a junior host who help the number one host in host club'.
\end{abstract}

Keywords: mizu shoubai, host club, host 


\section{Latar Belakang}

Mizu shoubai merupakan istilah untuk kehidupan malam di Jepang. Salah satu bagian yang termasuk dalam mizu shoubai adalah profesi host (hosuto). Kata host merupakan bentuk dalam bahasa Inggris yang memiliki pengertian 'tuan rumah' (Matsuura, 1994: 312). Kata ini kemudian berkonotasi menjadi pekerjaan dari pria heteroseksual 'memiliki ketertarikan terhadap lawan jenis' yang menawarkan berbagai macam layanan persahabatan kepada pelanggan wanitanya (Yamagishi, 2009: 10). Para host bekerja di sebuah tempat yang disebut dengan host club (hosuto kurabu).

Bisnis ini merupakan pekerjaan dari pria heteroseksual 'memiliki ketertarikan terhadap lawan jenis' yang menawarkan berbagai macam layanan persahabatan kepada pelanggan wanitanya (Fukazawa, 2002; Takeyama, 2005 dalam Yamagishi, 2009: 10).

\section{Pokok Permasalahan}

Rumusan masalah dalam penelitian ini adalah sebagai berikut:

1. Bagaimanakah kriteria untuk menjadi host yang tercermin dalam manga Hosutan e Youkoso karya Makoto Tateno?

2. Bagaimanakah profesi host yang tercermin dalam manga Hosutan e Youkoso karya Makoto Tateno?

\section{Tujuan Penelitian}

Tujuan dari penelitian ini adalah memahami kriteria untuk menjadi host serta memahami profesi host yang tercermin dalam manga Hosutan $e$ Youkoso karya Makoto Tateno.

\section{Metode Penelitian}

Sumber data yang digunakan dalam penelitian ini adalah manga Hosutan e Youkoso karya Tateno (2008-2009). Sedangkan, metode yang digunakan untuk menganalisis data adalah metode kualitatif dan teknik deskriptif analisis (Ratna, 2009). Penelitian ini menggunakan teori sosiologi sastra dari Ratna (2009) serta teori trilogi sastra dari Wellek dan Warren (1993) untuk menganalisis kriteria untuk menjadi host serta profesi host. Di samping itu, digunakan pula teori semiotika dari Danesi (2012) untuk menganalisis tandatanda pada gambar dalam manga.

\section{Hasil dan Pembahasan}

\subsection{Kriteria Fisik Untuk Menjadi Host}

Kriteria fisik merupakan suatu kriteria paling nyata yang dapat dirasakan oleh indera manusia, yang terdiri atas indra penglihatan, pendengaran, penciuman, peraba, dan perasa (Gea, 2006: 18). Berikut ini penjabaran mengenai kriteria fisik untuk menjadi host.

\subsubsection{Memiliki Wajah yang Menarik}

Wajah menjadi salah satu hal penting dalam bisnis ini karena host merupakan suatu pekerjaan yang menuntut seseorang untuk menjaga penampilan fisik mereka (Yamagishi, 2009: 161). Wajah menarik dari seorang host dapat dilihat dalam gambar berikut.

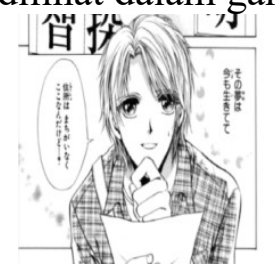

\section{Gambar (1) Wajah Kobayashi}

(Hosutan e Youkoso, 2008: 5)

Gambar (1) tersebut adalah gambar wajah Kobayashi. Berdasarkan gambar (1) tersebut, dapat diketahui bahwa Kobayashi memiliki wajah yang terlihat lugu atau polos. Di samping itu, Kobayashi juga digambarkan memang memiliki wajah yang imut. Dengan wajahnya yang imut tersebut, beberapa 
host tidak percaya bahwa usia Kobayashi sudah 20 tahun.

\subsubsection{Berpenampilan yang Baik}

Apabila seorang host menampilkan sebuah penampilan yang berkesan mahal terhadap para pelanggannya, maka akan terdapat kemungkinan bahwa pelanggan tersebut juga akan memberikan host hadiah yang mahal (Yamagishi, 2009: 225). Penampilan yang baik dari seorang host tersebut dapat dilihat dalam gambar berikut.

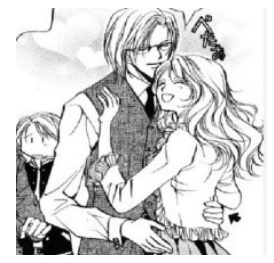

Gambar (2) Gaya Penampilan Akechi

(Hosutan e Youkoso, 2008: 34)

Berdasarkan gambar (2) tersebut, dapat dilihat bahwa pada saat itu Akechi memilih kacamata sebagai aksesorisnya dan ia menggunakan kemeja lengan panjang berdasi yang dipadukan dengan rompi sebagai pakaiannya. Hal tersebut membuktikan bahwa host memiliki selera penampilan yang baik, sehingga penampilan yang ditunjukkan mampu membuat orang lain terkagum-kagum dan mampu menarik hati para pelanggan. Kekaguman tersebut dapat dilihat melalui senyum yang ditunjukkan oleh Hanako ketika melihat penampilan Akechi.

\subsection{Kriteria Non Fisik Untuk Menjadi Host \\ Kriteria non fisik adalah kriteria} yang tidak dapat dirasakan oleh indera manusia. Kriteria non fisik ini tidak dapat dilihat, didengar, dibaui, diraba, dan dirasakan. Berikut ini penjabaran mengenai kriteria non fisik untuk menjadi host.

\subsubsection{Memiliki Toleransi Tinggi Terhadap Minuman Beralkohol \\ Setiap harinya, host memang} mengkonsumsi minuman beralkohol dalam jumlah yang sangat banyak (Yamagishi, 2009: 217) karena mereka dapat menghasilkan uang melalui percakapannya dengan wanita dan minuman beralkohol (Yamagishi, 2009: 308). Toleransi tinggi yang dimiliki oleh host terhadap minuman beralkohol tersebut dapat dilihat dalam gambar berikut.

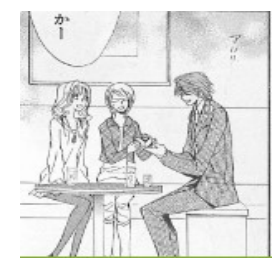

Gambar (3) Akane Melayani

Dua Pelanggan dalam Satu Meja

(Hosutan e Youkoso, 2009: 110)

Gambar (3) adalah gambar ketika Akane melayani dua pelanggan dalam satu meja. Di sebuah host club, pelanggan diharapkan untuk tidak hanya memesan segelas alkohol, namun mereka diharapkan memesan sebotol alkohol (Yamagishi, 2009: 158). Oleh karena itu, apabila di meja Akane terdapat dua orang pelanggan, itu berarti terdapat pesanan dua botol alkohol. Dengan demikian, hal tersebut membuktikan bahwa host harus memiliki toleransi tinggi terhadap minuman beralkohol.

\subsubsection{Memiliki Keterampilan dalam Berkomunikasi \\ Untuk menjadi host, seseorang juga} harus memiliki keterampilan dalam berkomunikasi dengan wanita, terutama secara lisan dan emosional (Yamagishi, 2009: 278). Keterampilan berkomunikasi dari seorang host dapat dilihat dalam data berikut. 
(1)

$\begin{array}{cl}\text { Akane } & \text { : Oya, ikenai hito } \\ & \text { dana... Yoso mi suru } \\ & \text { nante boku ja fuman? } \\ \text { Okyaku } & \text { Yada, Gomeen. Uso } \\ & \text { uso Akane ga } \\ & \text { ichiban yo. }\end{array}$

(Hosutan e Youkoso, 2009: 83)

\begin{tabular}{|c|c|}
\hline Akane & $\begin{array}{l}\text { : Wah, sampai melirik } \\
\text { yang lain, apa aku } \\
\text { tidak memuaskan? }\end{array}$ \\
\hline Pelanggan: & $\begin{array}{l}\text { Duh, maaf. Akane } \\
\text { masih yang nomor } \\
\text { satu, kok. }\end{array}$ \\
\hline
\end{tabular}

Data (1) tersebut adalah percakapan antara Akane dengan salah satu pelanggannya. Pada data (1) tersebut, Akane yang merasa tidak dihiraukan, menegur pelanggannya. Tegurannya tersebut ia lakukan secara sopan dan tidak sampai membuat pelanggannya marah. Teguran yang dilakukan oleh Akane tersebut adalah teguran yang halus, sopan, dan lembut, sehingga pelanggan yang ia tegur pun membalasnya dengan jawaban yang juga sopan. Hal tersebut menunjukkan bahwa, keterampilan dalam berbicara sangat diperlukan untuk menjadi host karena dengan keterampilan tersebut seorang host dapat membuat para pelanggan merasa nyaman.

\subsubsection{Memiliki Wawasan yang Luas}

Seperti yang telah dijelaskan sebelumnya, untuk bekerja dalam industri ini, seorang host juga harus memiliki wawasan yang luas untuk melayani pelanggan kelas atas (Yamagishi, 2009: 22). Wawasan luas yang dimiliki oleh host dapat dilihat melalui data berikut.

(2) Akechi : Sukaafu no teire no shikata wa benjin wo ookime no bin ni $1 / 3$ hodo ire naka ni sukaafu wo irete furi arai wo suru. Ato wa, karuku shibotte kaze ni atete kawakasu.

Airon wo ateru toki

wa shinchou ni ka ki

ni totemo hannou shi

yasui mono dakara.

(Hosutan e Youkoso, 2009: 90-91)

Akechi $\quad$ Cara merawat scarf
adalah dimasukkan
ke dalam wadah
besar yang $1 / 3$
bagiannya terisi
bensin. Kemudian,
diperas dengan
lembut dan diangin-
anginkan sampai
kering. Harus
berhati-hati saat
disetrika karena
sangat mudah
bereaksi terhadap api.

Data (2) tersebut adalah data yang diucapkan oleh Akechi ketika ia menjelaskan mengenai cara merawat scarf kepada Madam Yoko. Melalui penjelasan Akechi tersebut, dapat diketahui bahwa Akechi mengetahui secara detail cara merawat scarf. Dengan demikian, dapat dibuktikan bahwa host memiliki wawasan yang luas.

\subsubsection{Mampu Menyesuaikan Diri dengan Kebutuhan Pelanggan}

Untuk menjadi populer dihadapan wanita, ada beberapa macam hal yang harus diketahui oleh host. Hal-hal tersebut meliputi, sikap yang tepat, penampilan, cara bercakap-cakap, cara berkencan, cara melakukan seks, cara untuk berpisah, cara untuk mendapatkan wanita, kemampuan untuk membaca pikiran wanita, dan yang lainnya (Aida, 2002; Eguchi, 1999; Reiji, 1999; Shirosaki, 2005; Yoritomo, 2007 dalam Yamagishi, 2009: 253). Kemampuan host untuk menyesuaikan diri dengan 
kebutuhan pelanggan tersebut dapat dilihat melalui gambar berikut.

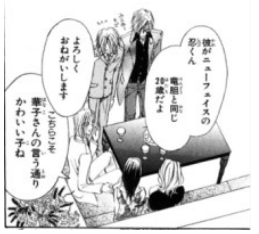

Gambar (4) Sikap Shinobu Saat Mempernalkan Diri

(Hosutan e Youkoso, 2008: 60)

Gambar (4) tersebut adalah gambar ketika Shinobu diperkenalkan kepada beberapa orang pelanggan oleh Akechi. Melalui gambar (4) tersebut, dapat dilihat bahwa Shinobu melakukan ojigi. Dalam gambar tersebut, ia melakukan ojigi dengan meletakkan tangannya di samping kiri dan kanan dan ia mengucapkan yoroshiku onegaishimasu 'mohon bantuannya'. Hal tersebut juga membuktikan bahwa ia mampu menyesuaikan diri dengan kebutuhan pelanggan.

\subsubsection{Berusia 20 Tahun Hingga 30 Tahunan}

Usia rata-rata dari seorang host dalam industri host club modern adalah usia di awal 20 tahunan, sedangkan host tertua adalah host yang berada pada usia pertengahan 30-an atau akhir 30-an (Yamagishi, 2009: 279). Usia dari seorang host tersebut dapat dilihat dalam data berikut.
(3) Rindo : Omae 20 sai tte maji?

Kobayashi: Sou desuyo. Rindo san tame desho?

Rindo : Ou, totemo onaji toshi to wa omoenee kedo na.

Kobayashi: Nan da yo. Socchi no ga fuketeru dake jan.

(Hosutan e Youkoso, 2008: 19)

\section{Rindo : Apa kau benar-benar 20 tahun?}

Kobayashi: Iya, seumur denganmu, kan?

Rindo : Iya, tapi sama sekali tidak ku sangka kita seumur.

Kobayashi: Apa maksudmu? Bukannya itu berarti kau yang mukanya boros!?

Berdasarkan data (3), dapat diketahui bahwa Kobayashi dan Rindo memiliki usia yang sama, yaitu 20 tahun. Bisnis host club ini membutuhkan para pria yang berusia muda untuk bekerja di dalamnya karena mereka dianggap masih memiliki tubuh yang kuat dan sehat, terutama untuk melakukan pekerjaan yang cukup berat seperti host.

\subsection{Tugas Host}

Penelitian ini membahas tiga tugas host yaitu menyambut pelanggan, menemani atau bergabung dengan pelanggan untuk melakukan percakapan, serta memberikan perhatian kepada pelanggan.

\subsubsection{Menyambut Pelanggan}

Biasanya para host menyambut pelanggan dengan mendatangi pintu masuk dan memberikan sapaan yang sangat ceria (Yamagishi, 2009: 4). Menyambut pelanggan dapat dilihat dalam gambar berikut.

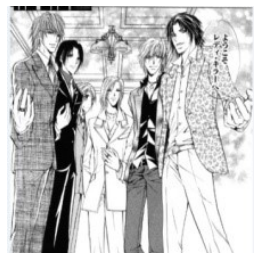

Gambar (5) Para Host Lady

Killer Menyambut Pelanggan

(Hosutan e Youkoso, 2008: 56)

Gambar (5) terjadi pada saat para host Lady Killer menyambut kedatangan 
pelanggan yang berkunjung ke host club Lady Killer. Dengan sambutan yang dilakukan oleh para host, pelanggan merasa dihargai dan dihormati. Hal ini sesuai dengan fungsi dari keberadaan host club itu sendiri yaitu untuk menciptakan sebuah tempat bagi para wanita yang ingin melepaskan diri dari kenyataan dan kesepiannya untuk sementara waktu (Yamagishi, 2008: 196).

\subsubsection{Menemani Pelanggan}

Selain menyambut kedatangan pelanggan, salah satu tugas host selanjutnya yaitu menemani pelanggan (Yamagishi, 2009: 7). Menemani pelanggan dapat dilihat dalam gambar berikut.

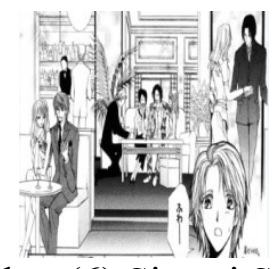

Gambar (6) Situasi Saat Host Menemani Pelanggan

(Hosutan e Youkoso, 2008: 75)

Gambar (6) adalah gambar yang menunjukkan situasi pada saat host menemani pelanggan yang ada di host club. Dalam gambar tersebut, dapat dilihat bahwa host menemani pelanggannya dengan cara duduk serta minum bersama dengan pelanggannya.

\subsubsection{Memberikan Perhatian kepada Pelanggan}

Untuk membangun dunia fantasi bagi wanita, para host bahkan memperhatikan perubahan-perubahan kecil yang terjadi pada pelanggannya (Takeyama, 2005: 2). Memberikan perhatian yang dilakukan oleh host kepada pelanggan dapat dilihat dalam data berikut.
(4) Akechi : Youkoso Redi Kiraa
e. Kousui kaeta?
Okyaku 1 : Ara wakaru?

\author{
Shiranui : O, atarashii fuku \\ niau na... \\ Okyaku 2 : Arigatou. \\ Akane : Sono shinshoku \\ suteki da ne.
}

(Hosutan e Youkoso, 2008: 57)

$\begin{aligned} \text { Akechi } & \text { : Selamat datang di } \\ & \text { Lady Killer. } \\ & \text { Parfummu ganti? }\end{aligned}$

Pelanggan 1: Wah, tahu ya?

Shiranui : Wah, baju baru, cocok sekali, lho...

Pelanggan 2: Terimakasih.

Akane : Warna lipstik itu cantik.

Data (4) adalah percakapan yang terjadi antara para host dengan pelanggannya. Dalam data tersebut, Akechi, Shiranui, serta Akane menunjukkan perhatiannya kepada pelanggan masing-masing. Hal tersebut membuktikan bahwa memberikan perhatian kepada pelanggan juga merupakan salah satu tugas host.

\subsection{Level Host}

Menjadi nomor satu di sebuah host club berarti tidak lagi bekerja sebagai herupu, namun ia berhak membuat seorang herupu mengkonsumsi minuman beralkohol atas namanya sendiri (Yamagishi, 2009: 238). Berikut penjabaran mengenai level host ini.

\subsubsection{Host Nomor Satu}

Sesuatu yang menjadi pemikat dalam industri ini adalah menjadi host yang berkarisma atau super host (Yamagishi, 2009: 94). Host sebagai otoko no akogare 'idaman pria' dapat dilihat dalam data berikut.

(5) Kobayashi: Mote mote ssu ne, shochou...

Akechi : Iya iya.

(Hosutan e Youkoso, 2009: 64) 
Kobayashi: Bos populer sekali, ya...

Akechi : Tidak, kok.

Data (5) adalah data yang terjadi pada saat Kobashi memuji kepopuleran Akechi. Saat seseorang telah menjadi host nomor satu di sebuah host club, maka itu berarti bahwa ia selalu memiliki pelanggan yang mengunjunginya, hal tersebut membuatnya populer dalam bisnis ini dan mampu mendapatkan penghasilan tertinggi di sebuah host club.

\subsubsection{Host sebagai Herupu}

Herupu atau help biasanya dilakukan oleh para host baru (Yamagishi, 2009: 238). Host sebagai herupu tersebut dapat dilihat dalam data berikut.

(6) Akechi : Shinobu kun, 2 ban teeburu ni oshibori to отіzи...

Shinobu :Haaai.

Shiranui : Shinobu kun, yon ban teeburu ni aisu...

Shinobu : Haaai.

Akane : San ban teeburu $n i$ chaamu san nin bun...

Shinobu :Haaai.

(Hosutan e Youkoso, 2009: 74)

$\begin{array}{ll}\text { Akechi } & \begin{array}{l}\text { : Shinobu, meja } 2 \\ \text { minta handuk basah } \\ \text { dan air... }\end{array} \\ \text { Shinobu } & : \text { Baik. } \\ \text { Shiranui } & : \text { Shinobu, air untuk } \\ & \text { meja } 4 \ldots \\ \text { Shinobu } & \text { : Baik. } \\ \text { Akane } & \text { : Snack } 3, \text { untuk orang } \\ & \text { di meja 3... } \\ \text { Shinobu } & \text { : Baik. }\end{array}$

Data (6) adalah situasi saat seorang herupu melaksanakan perintah seniornya. Dari perkataan Shinobu yang mengatakan "baik" untuk menanggapi perintah dari para senior tersebut, maka dapat disimpulkan bahwa ia telah melaksanakan tugasnya sebagai seorang hегирu.

\subsection{Jam Kerja Host}

Host club biasanya membuka club nya sebanyak dua kali dalam satu hari. Membuka club mulai dari pukul tujuh atau delapan malam adalah pembukaan club pertama, sedangkan mereka membuka club-nya kembali setelah tengah malam yang nantinya ditutup pada pagi hari. (Yamagishi, 2009: 370). Jam kerja host dapat dilihat melalui data berikut.

(7) Akechi : Karera wa hosuto de tantei nan da yo.

Kobayashi: Hosuto de tantei...!?

Akechi : Sakki mo itta kedo tantei dake ja yatte ikenai kara ne.

Hiru wa tantei, yoru wa hosuto wo shinagara okyaku ga kuru no wo matterun da. Tantei no irai mo omise ni kuru. Okyaku sama kara no mono ga hotondo da shi ne.

(Hosutan e Youkoso, 2008: 13)

$\begin{array}{cl}\text { Akechi } & \text { : } \text { Mereka host } \\ & \text { sekaligus detektif. } \\ \text { Kobayashi: } & \text { Host } \text { sekaligus } \\ \text { detektif? } & \\ \text { Akechi } & \text { Tadi kan sudah } \\ & \text { kubilang kalau tidak } \\ & \text { bisa hanya dengan } \\ & \text { usaha kantor detektif. } \\ & \text { Jadi, siang detektif, } \\ & \text { malamnya menjadi } \\ & \text { host sambil } \\ & \text { menunggu } \\ \text { pelanggan datang. } & \text { Lagipula, } \\ \text { kebanyakan }\end{array}$


permintaan

penyelidikan datang

dari pelanggan klub.

(8) Rindo : Konna mappiruma ni toshokan da yo? Asa 5 ji ni kaiten mise shita noni.

Kobayashi: Yanara, netereba yokatta noni.

(Hosutan e Youkoso, 2008: 31)

$$
\begin{aligned}
\text { Rindo } \quad \text { Kita harus ke } \\
\text { perpustakaan di } \\
\text { siang bolong begini? } \\
\text { Padahal klub baru } \\
\text { tutup jam } 5 \text { pagi. }
\end{aligned}
$$

Kobayashi: Kalau tidak mau, silahkan tidur sana!

Data (7) dan data (8) adalah adalah data yang menunjukkan waktu buka dan waktu tutup dari host club Lady Killer. Melalui data (7) dapat diketahui bahwa host club Lady Killer dibuka pada malam hari, sedangkan melalui data (8) dapat diketahui bahwa waktu tutup host club Lady Killer adalah pada pagi hari tepatnya jam lima pagi.

\subsection{Penghasilan Host}

Penghasilan seorang host berasal dari dua sumber yaitu komisi dan gaji harian. (Yamagishi, 2009: 229). Penghasilan host dapat dilihat melalui data berikut.

(9) Shiranui : 4 ban teeburu, Pin

Don

itadakimashitaa!

Akane : 2 ban teeburu mo

Pin Don

itadakimashitaa!

Shigure : 6 ban teeburu, Don

Peri Goorudo

itadakimashita!

Kobayashi: Su...sugoi miku na...

(Hosutan e Youkoso, 2008: 162)

\author{
Shiranui : Meja 4, pesan \\ Pinkdom! \\ Akane : Meja 2 juga pesan \\ Pinkdom! \\ Shigure : Meja 6, pesan Dom \\ Perignon Gold!
}

Kobayashi: He...hebat...

Data (9) terjadi pada saat Shiranui, Akane, dan Shigure menyebutkan namanama minuman yang dipesan oleh pelanggannya masing-masing. Hargaharga minuman tersebut tidaklah murah. Pinkdom atau Dom Perignon Pink harganya kurang lebih 100.000 yen dan Dom Perignon Gold harganya kurang lebih 250.000 yen (Tateno, 2008: 162). Semakin banyak uang yang dihabiskan oleh pelanggan di host club, maka semakin besar pula komisi yang didapatkan oleh host.

\subsection{Identitas Host}

Ketika bekerja, host tidak menggunakan identitas aslinya. Mereka bekerja dengan menggunakan genjina 'nama samaran yang digunakan saat seseorang bekerja di industri seks' (Yamagishi, 2009: 440). Host bekerja menggunakan genjina dapat dilihat dalam data berikut.
(10) Akechi : A! Kobayashi kun! Janakatta! Shinobu
kun kocchi oide...!
(Hosutan e Youkoso, 2008: 22)

\section{Akechi : Ah! Kobayashi! Eh, bukan! Shinobu, ayo kemari...!}

Data (10) adalah data yang terjadi ketika Akechi memanggil Kobayashi dengan sebutan Shinobu. Shinobu merupakan nama samaran yang diberikan kepada Kobayashi untuk digunakannya bekerja sebagai host. 


\subsection{Host Club}

Untuk mendapatkan kegembiraan dan kebebasan, tidak hanya membutuhkan suasana khayalan, tetapi juga membutuhkan lingkungan yang mendukung (Takeyama, 2008: 107). Host club dapat dilihat dalam gambar berikut.

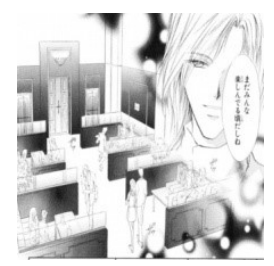

Gambar (7) Host Club Anti Ares

(Hosutan e Youkoso, 2009: 68)

Gambar (7) tersebut adalah gambar dari host club Anti Ares. Melalui gambar tersebut, dapat dilihat bahwa host club Anti Ares memilih warna hitam sebagai warna dominan untuk club-nya. Warna hitam tersebut diterapkan pada dinding, sofa, serta pembatas tempat duduk yang terdapat di dalam club-nya. Di tempat yang gelap sedemikian rupa, pelanggan tidak dapat melihat dengan jelas interaksi antara host dengan pelanggan lainnya (Yamagishi, 2009: 5).

\section{Simpulan}

Berdasarkan hasil penelitian terhadap manga Hsoutan e Youkoso, dapat disimpulkan bahwa kriteria untuk menjadi host terbagi menjadi dua kriteria yaitu, kriteria fisik dan non fisik. Kriteria fisik untuk menjadi host meliputi, memiliki wajah yang menarik serta berpenampilan yang baik. Selanjutnya, kriteria non fisik untuk menjadi host meliputi, memiliki toleransi tinggi terhadap minuman beralkohol, memiliki keterampilan dalam berkomunikasi, memiliki wawasan yang luas, mampu menyesuaikan diri dengan kebutuhan pelanggan, berusia 20 tahun hingga 30 tahunan.

Profesi host terbagi atas tugas host, level host, jam kerja host, penghasilan host, identitas host, serta host club. Tugas host terdiri dari tiga yaitu, menyambut pelanggan, menemani pelanggan, serta memberikan perhatian kepada pelanggan. Level host dibagi menjadi dua yaitu, host nomor satu dan host sebagai herupu.

\section{Daftar Pustaka}

Danesi, Marcel. 2012. Pesan, Tanda, dan Makna: Buku Teks Dasar Mengenai Semiotika dan Teori Komunikasi. Yogyakarta: Jalasutra.

Gea, Antonius Atoshoki. 2006. Integritas Diri: Keunggulan Pribadi Tangguh. Jakarta: Universitas Bima Nusantara.

Matsuura, Kenji. 1994. Kamus JepangIndonesia. Kyoto: Kyoto Sangyo University Press.

Ratna, Nyoman Kutha. 2009. Teori, Metode, dan Teknik Penelitian Sastra. Yogyakarta: Pustaka Pelajar.

Takeyama, Akiko. 2008. The Art of Seduction and Affect Economy: Neoliberal Class Struggle and Gender Politics in a Tokyo Host Club. UrbanaChampaign. University of Illinois at Urbana-Champaign.

Tateno, Makoto. 2008. Hosutan e Youkoso. Tokyo: Hakusensha, Inc.

Tateno, Makoto. 2009. Hosutan e Youkoso. Tokyo: Hakusensha, Inc.

Wellek, Rene dan Austin Warren. 1993. Teori Kesusastraan (Diterjemahkan dari Theory of Literature oleh Melani Budianta). Jakarta: PT. Gramedia Pustaka Utama.

Yamagishi, Reiko. 2009. A Promised Land For Men: The Rising Popularity Of Hosts in Contemporary Japanese Society. Singapore: National University Of Singapore. 